\title{
Quantification of Plasmodiophora brassicae Resting Spores in Soils Using Droplet Digital PCR (ddPCR)
}

\author{
Rui Wen, Jillian Lee, Mingguang Chu, Nazmoon Tonu, Tim Dumonceaux, Bruce D. Gossen, Fengqun Yu, and Gary Peng ${ }^{\dagger}$ \\ Saskatoon Research and Development Centre, Agriculture and Agri-Food Canada, Saskatoon, SK S7N 0X2, Canada
}

\begin{abstract}
Plasmodiophora brassicae, an obligate soilborne pathogen that causes clubroot on Brassica crops, is spreading rapidly in western Canada, threatening canola production in the region. Bioassays and molecular assays have been used to estimate the concentration of $P$. brassicae resting spores in soil, which can affect clubroot incidence and severity on crops. Droplet digital PCR (ddPCR) is a promising new approach for quantification of pathogen inoculum owing to its low sensitivity to inhibitors and consistency at low target concentrations. The objective of this study was to assess ddPCR against existing quantitative PCR (qPCR) for potential advantage and/or improvement in quantifying $P$. brassicae resting spores in soil. The new protocol enu-

of overestimation. The protocol was validated by quantifying the resting spores in spiked brown, dark brown, and black soils using both ddPCR and qPCR simultaneously. These soil types are found commonly on the Canadian Prairies, and they vary in texture, $\mathrm{pH}$, and organic content. ddPCR showed similar results among the different soil types, whereas qPCR often displayed lower counts for the same spore concentration, with the amplification of DNA inhibited completely in black soil samples. The inhibition can be removed by a 10-fold dilution of DNA samples. The results show that ddPCR can be a more versatile tool than qPCR for detection and quantification of $P$. brassicae resting spores in soil samples.
\end{abstract} merated resting spores accurately in spiked potting mix or soil samples ranging from $10^{2}$ to $10^{7}$ spores per gram. At a spore concentration $\geq 10^{7}$ spores per gram, however, ddPCR became less accurate, with a tendency
Keywords: canola, clubroot, ddPCR, Plasmodiophora brassicae, qPCR, resting spores
Clubroot, caused by the obligate protist pathogen Plasmodiophora brassicae Woronin, is a common disease on Brassica crops worldwide (Dixon 2009), and it has become a serious threat to canola (Brassica napus L) production in western Canada (Hwang et al. 2012; Strelkov and Hwang 2014). Severe infestation can result in nearly $100 \%$ yield loss (Rempel et al. 2014). Clubroot is spreading in western Canada (Gossen et al. 2015; Strelkov et al. 2018) through movement of infested soil, especially by field equipment (Cao et al. 2007; Gossen et al. 2014). Wind can also spread the spores across both short and long distances (Rennie et al. 2015). The minimum threshold of inoculum concentration in soil required to infect brassica plants to cause visible clubroot symptoms and crop losses is about $10^{3}$ spores per gram of dry soil (Donald and Porter 2009; Faggian and Strelkov 2009; Hwang et al. 2011). Management practices, including crop rotation (Peng et al. 2015) and fumigation (Hwang et al. 2018), can substantially reduce spore concentration in soil, thus mitigating the impact of clubroot. An integrated approach is recommended for clubroot management on canola, including use of resistant cultivars, extended crop rotation, and soil amendment (Cao et al. 2007; Peng et al. 2014).

Quantification of $P$. brassicae resting spores in soil is needed to assess the efficacy of management practices in reducing $P$. brassicae inoculum and the associated risk of clubroot in fields. The spores are

\section{${ }^{\dagger}$ Corresponding author: G. Peng; gary.peng@agr.gc.ca}

Funding: Funding for the study was provided by Western Grain Research Foundation \& SaskCanola project ADF20150064, the Canadian Agriculture Partnership of the Canola Council of Canada, and Agriculture and AgriFood Canada Canadian Agricultural Partnership funding.

*The $\boldsymbol{e}$-Xtra logo stands for "electronic extra" and indicates that supplementary figures are published online.

The author(s) declare no conflict of interest.

Accepted for publication 22 November 2019.

(๑) Her Majesty the Queen in Right of Canada, as represented by the Minister of Agriculture and Agri-Food Canada. extremely small (3- to 5- $\mu \mathrm{m}$ diameter) (Moxham and Buczacki 1983) and lack visible ornamentation, and therefore, direct counting of spores in soil using a light microscope would be highly variable, even for experienced individuals (Cranmer 2015). Bioassays based on the disease occurrence of a brassicae variety in infested soil samples have been used to determine if the soil would contain sufficient inoculum to cause infection and/or production losses (Wallenhammar 1996), but these methods are time and resource consuming (Cao et al. 2007). They are also highly variable because of patchy distribution of pathogen resting spores even within a small area of a field and subjective disease scoring (Wallenhammar et al. 2012). Antibodyrelated assays have also been developed, but they have seen limited applications owing to variability and cost (Cao et al. 2007; Cranmer 2015). Quantitative PCR (qPCR) assays have been developed for $P$. brassicae. These assays estimate the genomic DNA of $P$. brassicae using primers specific to the pathogen (Al-Daoud et al. 2017; Deora et al. 2015) on seed, in roots, and from soil (Anders et al. 2016; Cao et al. 2014; Ernst et al. 2019; Rennie et al. 2011; 2015; Wallenhammar et al. 2016).

qPCR provides rapid and highly specific quantification of $P$. brassicae DNA, but factors in the soil, such as heavy metals, clay particles, and humic substances, can inhibit the PCR process, affecting the accuracy of inoculum quantification (Deora et al. 2015; Matheson et al. 2010). Additionally, results may vary among laboratories if standard curves for qPCR are calibrated using different methods (Kuypers and Jerome 2017). Sample dilution is used commonly to reduce the effect of inhibition for PCR amplification, whereas the use of a competitive positive internal control (CPIC) can provide a direct estimate of the inhibition occurring in a sample (Deora et al. 2015). Propidium monoazide (PMA) penetrates the nonviable cells with damaged membranes, binding tightly to exposed DNA and inhibiting PCR amplification. On the contrary, viable cells with intact cell membranes tend to limit PMA from entering the cell, enabling strong qPCR signals despite the presence of the reagent (Cangelosi and Meschke 2014). This selective inhibition allows for estimation of viable resting spores in spore mixtures where some spores are immature or dead (Al-Daoud et al. 2017).

Droplet digital PCR (ddPCR) is a relatively new PCR technology based on generation of water-oil emulsion droplets that partition individual DNA molecules into separate droplets. Each droplet serves 
as an individual test tube in which amplification can take place. The high degree of sample partitioning provides a high-throughput platform that yields more accurate results compared with qPCR (Hindson et al. 2011). ddPCR is more resistant to amplification inhibitors than qPCR (Rački et al. 2014) because it partitions a single DNA sample into tens of thousands of individual reactions in oil droplets, and each droplet is analyzed to determine the fraction of PCRpositive droplets in the original sample. The total number of target molecules is calculated through Poisson statistics (Monteiro and Santos 2017). Therefore, the results are less affected by low amplification efficiency (Kuypers and Jerome 2017). ddPCR also provides direct quantification of input DNA with a high degree of sensitivity and accuracy (Kanagal-Shamanna 2016). Therefore, there is no need for standard curves, and results from different laboratories can be compared directly. ddPCR also has a higher signal-to-noise ratio than $\mathrm{APCR}$, which provides higher precision and sensitivity (Findlay et al. 2016). In a comparative study of several molecular techniques, CPIC-PCR and ddPCR provided better estimates of $P$. brassicae resting spore numbers in soil samples from a naturally infested field relative to qPCR (Gossen et al. 2019).

The objective of this study was to develop and refine a ddPCR protocol for efficient and reliable quantification of $P$. brassicae resting spores in different soils. After validated, the protocol can be used as a new tool to accurately detect and quantify resting spores of $P$. brassicae in soil for a range of applications in research and diagnostics.

\section{Materials and Methods}

Preparation of inoculum and soil. A field population of a pathotype X of P. brassicae (Strelkov et al. 2018), which is virulent on the first generation of clubroot-resistant canola cultivars available in Canada, was used throughout the study. Root galls of canola plants were homogenized in a blender with deionized water at a high speed for about $1 \mathrm{~min}$, and the homogenate was filtered through eight layers of cheesecloth to obtain a resting spore suspension. The concentration of suspension was measured with a hemocytometer, adjusted to $1 \times 10^{8}$ spores per milliliter, and used for serial dilution with deionized water to produce resting spore suspensions containing $10^{7}, 10^{6}$, $10^{5}, 10^{4}, 10^{3}$, and $10^{2}$ spores per milliliter. These spore suspensions were used for the extraction of $P$. brassicae genomic DNA and ddPCR assays. They were also used to infest soil samples in subsequent experiments.

Soilless potting mixes with high organic content are used routinely in clubroot research under controlled environment conditions. To assess the feasibility of quantifying $P$. brassicae inoculum in potting mixes using ddPCR, 1-g samples of Sunshine \#3 Mix (SunGro Horticulture) with $<15 \%$ of water content were inoculated with resting spore suspensions as a drench to produce inoculum concentrations of $0,10,10^{2}, 10^{3}, 10^{4}, 10^{5}, 10^{6}$, and $10^{7}$ resting spore per gram of mix. The samples were kept in petri dishes with the lid open to dry further at room temperature for 2 weeks before being ground to a fine powder using a mortar and pestle. The water content dropped to $<15 \%$ after the drying process. Subsamples of $0.1 \mathrm{~g}$ were taken from each of the infested potting mix samples and used for DNA extraction.

An additional eight potting mix samples infested by unknown amounts of resting spores were gathered randomly from a clubroot inoculation experiment. Based on the inoculum added at the beginning of experiment, it was estimated that the spore concentration would be around $1 \times 10^{5}$ to $1 \times 10^{7}$ spores per gram depending on the amount of root galls that remained in the growth medium. These samples were also dried at room temperature for 2 weeks; then, $0.1-\mathrm{g}$ subsamples were taken from each infested sample for DNA extraction. This set of subsamples was used for comparison between qPCR and ddPCR.

Extraction of DNA. The PowerSoil DNA Isolation Kit (Qiagen) was used to extract the DNA of $P$. brassicae in resting spore suspensions. Each suspension concentration $\left(0,10,10^{2}, 10^{3}, 10^{4}, 10^{5}, 10^{6}\right.$, and $10^{7}$ spores per milliliter) was made by a serial dilution of the initial preparation $\left(10^{8}\right.$ spores per milliliter). Aliquots of $0.1 \mathrm{ml}$ of spore suspension were pipetted into PowerBead Tubes and homogenized three times at $1 \mathrm{~min}$ each on the FastPrep-24 homogenizer
(MP Biomedicals) for cell lysis. Despite the use of the PowerSoil Kit, the cell lysis step enhanced the amount of DNA extracted from $P$. brassicae resting spores during a series of pretrial tests (data not shown). DNA from each sample was eluted in $200 \mu$ l of elution buffer included in the isolation kit, and all DNA preparations were stored at $-20^{\circ} \mathrm{C}$ until use.

Potting mix samples were dried in open petri dishes at room temperature for 2 weeks; then, a 0.1-g sample was added to a PowerBead Tube and homogenized three times with the FastPrep-24 homogenizer. DNA extraction followed the manufacturer's instructions, and samples were stored at $-20^{\circ} \mathrm{C}$ until use.

Primers and probes. The primers and probe used to amplify the internal transcribed spacer 1 region of $P$. brassicae (Table 1) were selected based on a previous study (Deora et al. 2015). The probe design was modified from the $5^{\prime}$ end reporter dye of fluorescein amidite (FAM) and the $3^{\prime}$ quencher of nonfluorescent quencher-minor groove binder to the $5^{\prime}$ end reporter dye of FAM and $3^{\prime}$ end of 3IABkFQ (fluorescence quenching) with a ZEN internal quencher (Supplementary Fig. S1). The primers and probe were synthesized by Integrated DNA Technologies Inc.

Quantification of $P$. brassicae resting spores with ddPCR. A QX200TM ddPCR System (Bio-Rad Laboratories) was used to quantify the resting spores of $P$. brassicae. All reagents and consumables, including droplet generator oil, DG8TM cartridges and gaskets, droplet reader oil, and ddPCR supermix for the probe, were purchased from Bio-Rad. For each sample, $20 \mu \mathrm{l}$ of reaction mix containing $10 \mu \mathrm{l}$ of probe supermix, $1 \mu \mathrm{l}$ each of forward and reverse primers $(22.5 \mu \mathrm{M}), 1 \mu \mathrm{l}$ of probe $(6.25 \mu \mathrm{M})$ and $5 \mu \mathrm{l}$ of sample complementary DNA was partitioned into aqueous droplets in oil via a droplet generator. The droplets were transferred to a 96-well PCR plate, and a thermocycling process was carried out in a conventional thermal cycler (Thermo Fisher Scientific Canada) at $95^{\circ} \mathrm{C}$ for $10 \mathrm{~min}$, $94^{\circ} \mathrm{C}$ for $30 \mathrm{~s}$ ( 40 cycles), $60^{\circ} \mathrm{C}$ (ramp rate: $2^{\circ} \mathrm{C} / \mathrm{s}$ ) for $60 \mathrm{~s}(40 \mathrm{cy}-$ cles), $98^{\circ} \mathrm{C}$ for $10 \mathrm{~min}$, and then, $4^{\circ} \mathrm{C}$ infinite. The PCR plate was then transferred to the droplet reader, and QuantaSoft Software (Bio-Rad) was used for data analysis. A threshold of 2,000 was set to differentiate positive droplets with a higher fluorescence amplitude relative to the background.

The initial ddPCR quantification was performed using $5 \mu l$ of DNA extracted from $0.1 \mathrm{ml}$ of each spore suspension $\left(10^{8}\right.$ to $10^{2}$ spores per milliliter) made with serial dilutions. The results (copies per microliter) were converted to resting spores per milliliter by multiplying the dilution factor $(400 \times)$ and spores counted in the suspension. To validate the result, serial dilutions were made with the $P$. brassicae genomic DNA extracted from a suspension with $1 \times 10^{7}$ spores per milliliter until $10^{-5}$, which would have the amount of DNA equivalent to that in the suspension carrying $10^{2}$ spores per milliliter. ddPCR was also performed on infested potting mix spiked with known numbers of $P$. brassicae resting spores.

To compare ddPCR with qPCR for quantifying the inoculum of $P$. brassicae in different soil types, topsoil (10-cm-deep) samples were collected at five random locations of a field in the brown, dark brown, and black soil zones of the Canadian Prairies near Swift Current, Outlook, and Melfort, Saskatchewan, respectively. These are the most common soil types found in the vast majority of crop regions on the prairies (Pennock 2005). Soil samples were dried at room temperature for 2 weeks; then, about $50 \mathrm{~g}$ of each soil was ground to a fine powder using a mortar and pestle. Soil $\mathrm{pH}$ was measured by mixing $20 \mathrm{~g}$ of each soil sample with $20 \mathrm{ml}$ of deionized water in a $100-\mathrm{ml}$ beaker, stirring for $30 \mathrm{~min}$, letting it stand for $1 \mathrm{~h}$, and testing with a

Table 1. The primers and probe used to amplify a segment of the internal transcribed spacer 1 region of Plasmodiophora brassicae

\begin{tabular}{lc}
\hline Primer/probe & Sequence $\mathbf{5}^{\prime}$ to $\mathbf{3}^{\prime}$ \\
\hline DC1F (primer) & CCT AGC GCT GCA TCC CAT AT \\
DC1mR (primer) & CGG CTA GGA TGG TTC GAA A \\
PB1 (probe) & 5'-/56-FAM/CCA TGT GAA/ZEN/ \\
& CCG GTG ACG TGCG/3IABkFQ/-3' \\
\hline
\end{tabular}


pH/ORP Cal Check Bench Meter (ESP Chemicals Inc.). Additional 20 -g soil samples were placed in a drying oven at $60^{\circ} \mathrm{C}$ for 5 days to remove the soil moisture. After cooling, multiple 1-g subsamples were taken from each soil type, and a serial dilution of $P$. brassicae resting spore suspensions at $10^{3}, 10^{4}, 10^{5}, 10^{6}$ and $10^{7}$ spores per milliliter was added to each subsample at a 1:1 ratio (wt/vol) and mixed thoroughly to produce spiked soil samples carrying about $10^{3}, 10^{4}$,
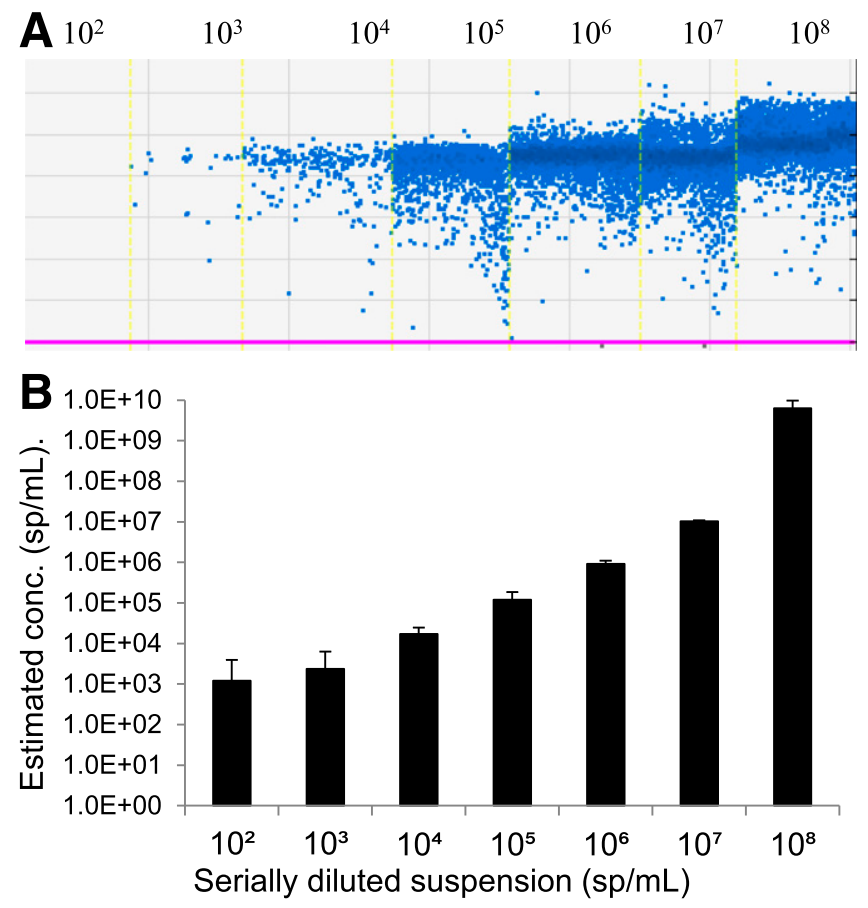

Fig. 1. Quantification of Plasmodiophora brassicae resting spores in suspension with droplet digital PCR. A, PCR amplification with each blue dot representing a droplet containing fluorescein amidite-labeled DNA fragments. B, Estimated concentration of resting spores for each serial dilution of spore suspension.
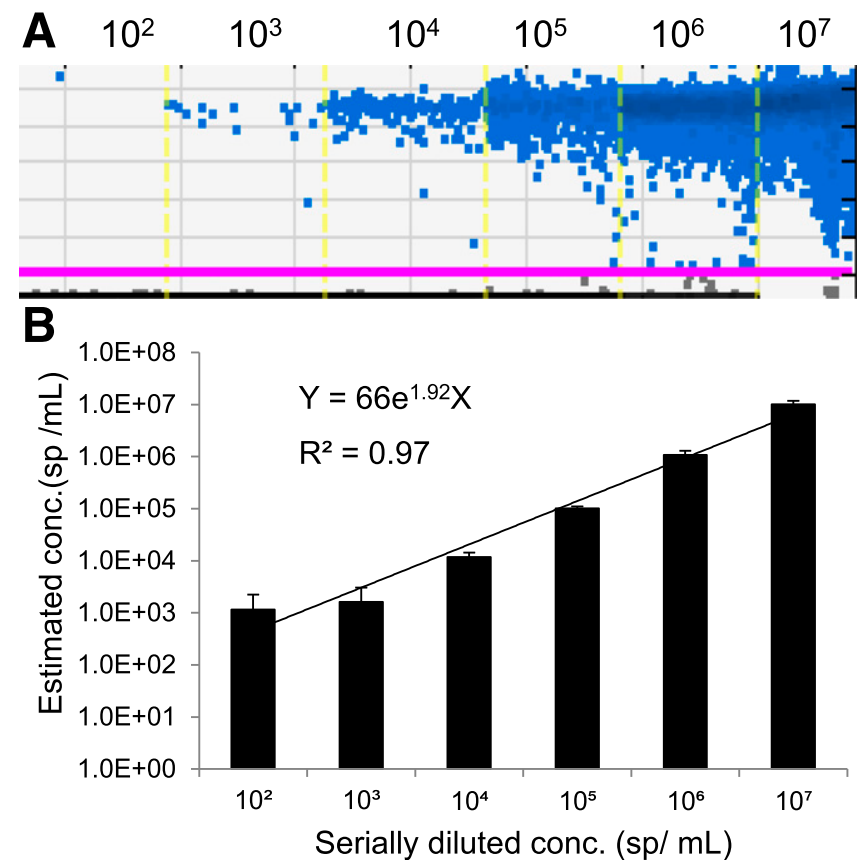

Fig. 2. Estimation of resting spore concentration using droplet digital PCR (ddPCR) based on serial dilutions of Plasmodiophora brassicae genomic DNA created from an initial resting spore suspension of $1 \times 10^{7}$ spores per milliliter. A, PCR amplification, where the blue dots represent the droplets containing labeled DNA fragment. B, Resting spore concentrations estimated using ddPCR relative to serial dilutions of genomic DNA.
$10^{5}, 10^{6}$, and $10^{7}$ spores per gram. Each infested subsample was kept in a petri dish without covering at room temperature for 2 weeks and then, ground to a fine powder again using a mortar and pestle. A $0.1-\mathrm{g}$ sample was taken from each subsample of soil and homogenized with the FastPrep-24 prior to DNA extraction. The protocol for ddPCR quantification was as described above. qPCR (described below) was also performed on the same DNA samples for comparison. Three replicates were prepared independently for each inoculum concentration of each soil type. The experiment was repeated once for ddPCR but twice for qPCR because of strong inhibition of DNA amplification with black soil samples. The inhibition was removed by a 10-fold dilution of DNA samples.

Quantification of $\boldsymbol{P}$. brassicae resting spores with qPCR. Eight samples were selected at random from 114 samples of potting mix infested by resting spores of $P$. brassicae from a separate study. These eight samples were homogenized using FastPrep-24 as described above, DNA extracted with the PowerSoil Kit, and analyzed with both ddPCR and qPCR (qPCR2) quantification. DNA samples were diluted five times with double-deionized water $\left(\mathrm{ddH}_{2} \mathrm{O}\right)$ to alleviate the inhibitor effect observed in pretrial qPCR tests (Supplementary Fig. S2). This dilution level was lower than that used for black soil samples described above (i.e., 10-fold) because of stronger inhibition factors present in the black soil. The qPCR reaction was performed on a Step-one real-time PCR system (Applied Biosystems) following the manufacturer's instructions. The PCR reaction was carried out in a $20-\mu l$ reaction volume consisting of $5 \mu \mathrm{l}$ of template DNA, $10 \mu \mathrm{l}$ of SYBR green, $2 \mu \mathrm{l}$ of primers, and $3 \mu \mathrm{l}$ of $\mathrm{ddH}_{2} \mathrm{O}$. Two technical replicates were used for each sample tested. Previously, these eight samples had been tested for resting spore concentration at Pest Surveillance Initiative (Winnipeg, MB) also using qPCR (qPCR1) following a reported protocol (Rennie et al. 2011). The PowerSoil Kit (Qiagen) was used to extract genomic DNA from resting spores in soil samples for both qPCR1 and qPCR2, but the homogenization equipment used prior to DNA extraction was different; qPCR1 used a bead ruptor (Omni Int.), whereas qPCR2 used the FastPrep-24. The rest of process remained the same for the two qPCR protocols, including the use of markers reported earlier (Cao et al. 2007).

Data analysis. All experiments were repeated once unless indicated otherwise, and all data were normally distributed based on the Shapiro-Wilk Test (Razali and Wah 2011). The variance from repeated experiments was homogeneous based on Bartlett's Test (Little and Hills 1978), and therefore, the data were pooled for analysis. The ddPCR and qPCR data from eight selected samples of infested potting mix from a separate study were compared using a $t$ test at $P=$ 0.01 . The estimates of resting spore concentration in soil types were subject to analysis of variance using Proc ANOVA in SAS (SAS Institute Inc.), and the means were separated based on least significant difference (LSD) at $P=0.05$.

\section{Results}

ddPCR quantification of $P$. brassicae spore suspension and serial dilutions of DNA. The number of copies of $P$. brassicae genomic DNA detected in suspensions increased as the resting spore concentration increased from $10^{2}$ to $10^{8}$ spores per milliliter (Fig. $1)$. The ddPCR estimates of spore concentration generally matched the expected number of resting spores in suspensions between $10^{3}$ and $10^{7}$ spores per milliliter, but the accuracy was reduced at $10^{2}$. and $10^{8}$-spores per milliliter levels because of apparent overestimation against the theoretical numbers based on the dilution (Fig. 1). The estimates of resting spore concentration based on ddPCR quantification of serially diluted $P$. brassicae DNA also matched the expected values closely, except for the $10^{-5}$ dilution, which was expected to be equivalent to $1 \times 10^{2}$ spores per milliliter (Fig. 2 and Table 2); ddPCR overestimated the number of resting spores based on the dilution factor observed between $10^{-4}$ and $10^{-5}$ dilution levels.

Quantification of inoculum in soilless potting mix. Estimates of resting spore concentration based on ddPCR analysis of samples spiked with $P$. brassicae suspensions in a dilution series from $1 \times$ $10^{2}$ to $1 \times 10^{7}$ resting spores per milliliter showed an excellent match 
with expected values (Fig. 3). For quantification with qPCR, a standard curve of $P$. brassicae resting spore concentration associated with the number of quantification cycles was established (Fig. 4A) using diluted genomic DNA extracted from spiked potting mix, with strong correlation coefficient $\left(R^{2}=0.993\right)$. Tests of eight random samples of infested potting mix with ddPCR and two qPCR protocols showed slightly varied numbers of resting spores; for the same sample, ddPCR generally found higher numbers of resting spores relative to qPCR (Fig. 4B), especially against qPCR1, which used a different DNA extraction protocol from that of ddPCR. This result indicates that ddPCR is more sensitive than qPCR in quantifying resting spores of $P$. brassicae in this type of growth media.

Comparison of ddPCR and qPCR in different soil types. Soil samples collected from crop fields representing the brown, dark brown, and black soil zones on the Canadian Prairies differed in texture and pH (Fig. 5A). Despite these variations, no differences were observed on ddPCR estimates of resting spore concentration among spiked samples of different soil types $\left(P>0.05\right.$, LSD) carrying $10^{3}$ to $10^{7}$ spores per gram of soil (Supplementary Fig. S3). qPCR often displayed lower resting spores on the same soil sample, especially when the inoculum level was at $<10^{6}$ spores per gram (Fig. 5B). Initially, DNA amplification was inhibited completely for samples of black soil. A 10-fold dilution of DNA extracts alleviated the inhibitory effect, resulting in similar numbers of estimated resting spores to those in brown soil samples. However, both still showed lower estimated spore numbers relative to those in the brown soil (Supplementary Fig. S4).

\section{Discussion}

The focus of this study was to evaluate ddPCR as a new tool to quantify $P$. brassicae resting spore concentration in different soil types for uses in research and diagnostic services. In a previous study, qPCR, CPIC-PCR, PMA-PCR, and ddPCR produced similar patterns of decline in resting spores in a field over time following a susceptible canola crop (Gossen et al. 2019). The information, however, was unavailable on the impact of soil type on ddPCR estimation of resting spore concentration. Our hypothesis was that ddPCR could provide more reliable estimates of resting spores in soils for several reasons. First, it is less affected by inhibiting factors in soil relative to qPCR (Rački et al. 2014); second, each DNA sample would be partitioned into about 20,000 nanoliter-sized droplets, and PCR amplification is carried out within each droplet (Kuypers and Jerome 2017). Third, ddPCR quantifies the actual copies of DNA, which would give an absolute value for the result without the need for a calibration series. This study demonstrated that ddPCR can provide sensitive and accurate estimates of $P$. brassicae resting spores $\left(\leq 10^{7}\right)$ in suspension, soilless potting mix, and infested field soils that differed in texture and $\mathrm{pH}$. At $>10^{7}$-spores per milliliter concentrations, ddPCR may overestimate the inoculum level, and this aspect will be discussed further below.

Resting spores of $P$. brassicae have a strong cell wall composed predominantly of chitin, enmeshed lipid-containing granules, and proteinaceous fibers (Buczacki and Moxham 1983). Although the PowerSoil Kit does not specify the need for cell lysis, the amount of DNA extracted from resting spore suspensions between $10^{3}$ and $10^{8}$ per milliliter was generally low when a cell lysis step was not used. Rennie et al. (2011) used a bead ruptor to facilitate the release of DNA from P. brassicae resting spores. We tested the TissueLyser
II (Qiagen), 0.1 M NaOH (Martin et al. 2000), and the FastPrep-24 homogenizer, and the latter consistently resulted in the highest amount of DNA extracted from the spore suspensions of $1 \times 10^{3}$ to $1 \times 10^{7}$ spores per milliliter. The quantification with ddPCR also

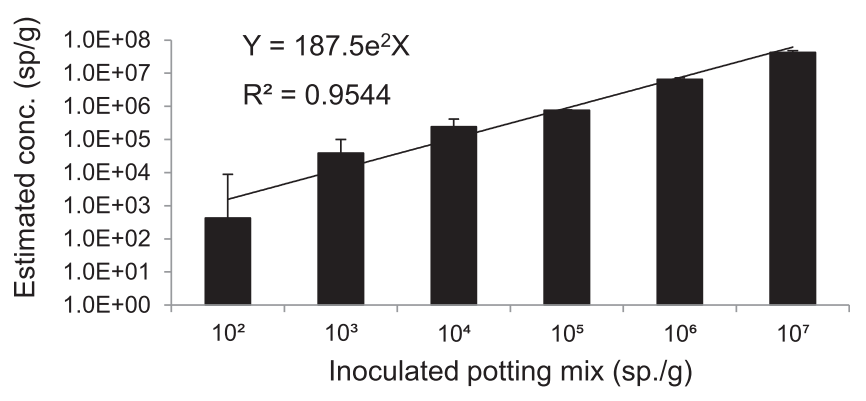

Fig. 3. Estimates of Plasmodiophora brassicae resting spores in soilless potting mix spiked with the pathogen spores using droplet digital PCR. The estimates were based on a total of six samples per spiked concentration of inoculum from two repeated tests. Materials and inoculum were prepared independently for each trial repetition.

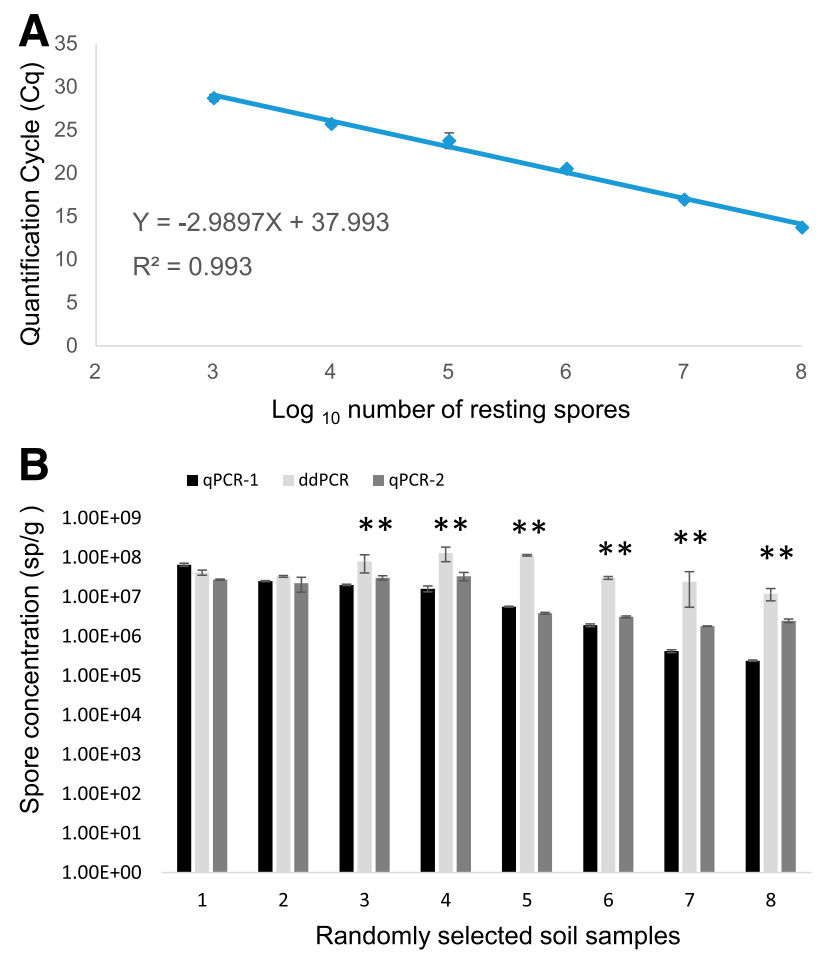

Fig. 4. Quantification of resting spores of Plasmodiophora brassicae in infected potting mix from a companion study using quantitative PCR ( $(\mathrm{PCR}$ ) and droplet digital PCR (ddPCR). A, Standard curves of $P$. brassicae resting spores concentration with quantification cycle $(\mathrm{Cq})$ value. B, Comparison of ddPCR and two qPCR protocols for quantifying the resting spores. QPCR1 and qPCR2 used slightly different equipment for cell lysis during DNA extraction; qPCR1 used a bead ruptor, whereas qPCR2 used a FastPrep-24 homogenizer. ddPCR also used the FastPrep-24 for cell lysis. ${ }^{*}$ Number of resting spores detected with ddPCR is significantly different from the number of resting spores detected using qPCR ( $t$ test, $P<0.01$ ).

Table 2. Estimates of resting spore concentration based on droplet digital PCR (ddPCR) analysis of serial dilutions of Plasmodiophora brassicae genomic DNA extracted from a highly concentrated resting spore suspension $\left(10^{7}\right.$ spores per milliliter)

\begin{tabular}{lccc}
\hline $\begin{array}{l}\text { Serial dilution of DNA } \\
\text { (equivalent to spores per } \mathbf{1} \mathbf{~ m l})\end{array}$ & $\begin{array}{c}\text { DNA copies }(\mathbf{2 0} \boldsymbol{\mu l}) \\
\text { detected with } \mathbf{~ d d P C R}\end{array}$ & $\begin{array}{c}\text { Conversion of DNA copies to } \\
\text { no. of resting spores per } \mathbf{1} \text { ml }\end{array}$ & $\begin{array}{c}\text { Observed dilution factor based } \\
\text { on ddPCR measurements }\end{array}$ \\
\hline $10^{-5}\left(1 \times 10^{2}\right)$ & 5.80 & 1,160 & 0.720 \\
$10^{-4}\left(1 \times 10^{3}\right)$ & 8.05 & 1,610 & 0.137 \\
$10^{-3}\left(1 \times 10^{4}\right)$ & 58.6 & 11,700 & 0.116 \\
$10^{-2}\left(1 \times 10^{5}\right)$ & 507 & 101,000 & 0.094 \\
$10^{-1}\left(1 \times 10^{6}\right)$ & 5,410 & $1,080,000$ & 0.107 \\
$0\left(1 \times 10^{7}\right)$ & 50,400 & $10,100,000$ & Not applicable \\
\hline
\end{tabular}


matched the inoculum added (data not shown). It is clear that homogenization is necessary for releasing the maximum amount of DNA from $P$. brassicae resting spores when used with the PowerSoil isolation kit; both FastPrep-24 and bead ruptor can substantially enhance the efficiency of DNA extraction. With the same samples of infested potting mix, qPCR1 (bead ruptor) resulted in slightly lower inoculum estimates at concentrations $<10^{7}$ spore per gram relative to those of qPCR2 (Fig. 4B). More work would be required to determine the efficiency of the two homogenization methods for cell lysis with a greater number of samples, but this is beyond the scope of this study.

Occasionally, ddPCR quantification of resting spores in suspension exceeded the number expected. This could be caused by spore clusters in suspensions that were counted as a single spore. Resting

\section{A Brown}

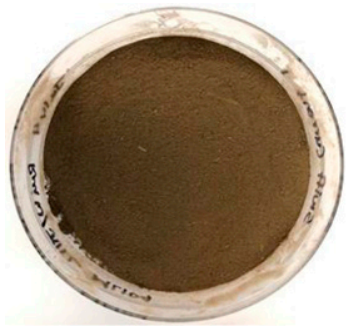

$\mathrm{pH}: 5.1 \pm 0.1$
Dark brown

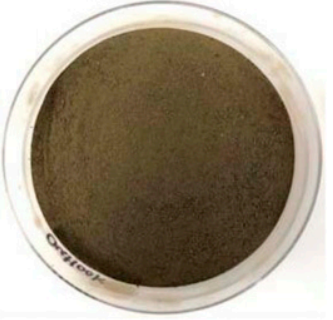

$\mathrm{pH}: 8.4 \pm 0.1$
Black

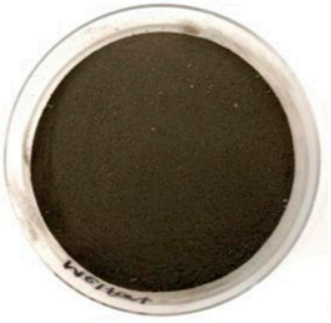

$\mathrm{pH}: 5.5 \pm 0.5$

B
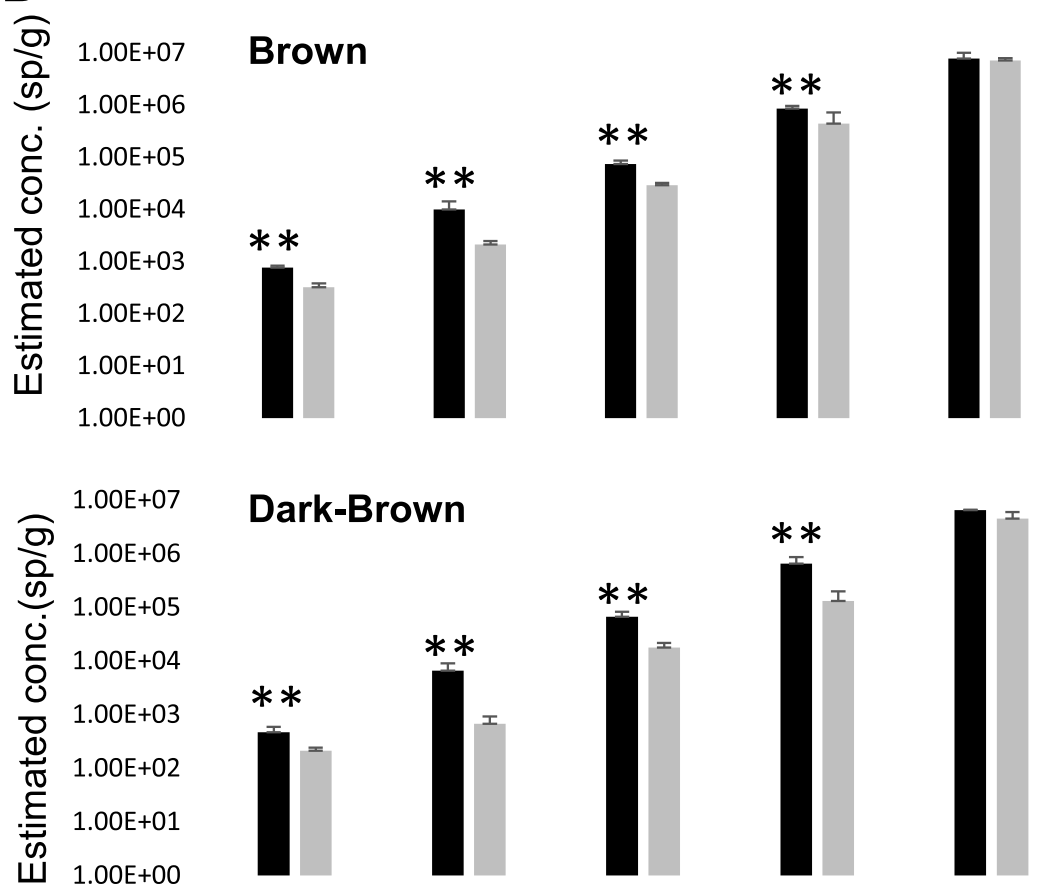

\section{Dark-Brown}

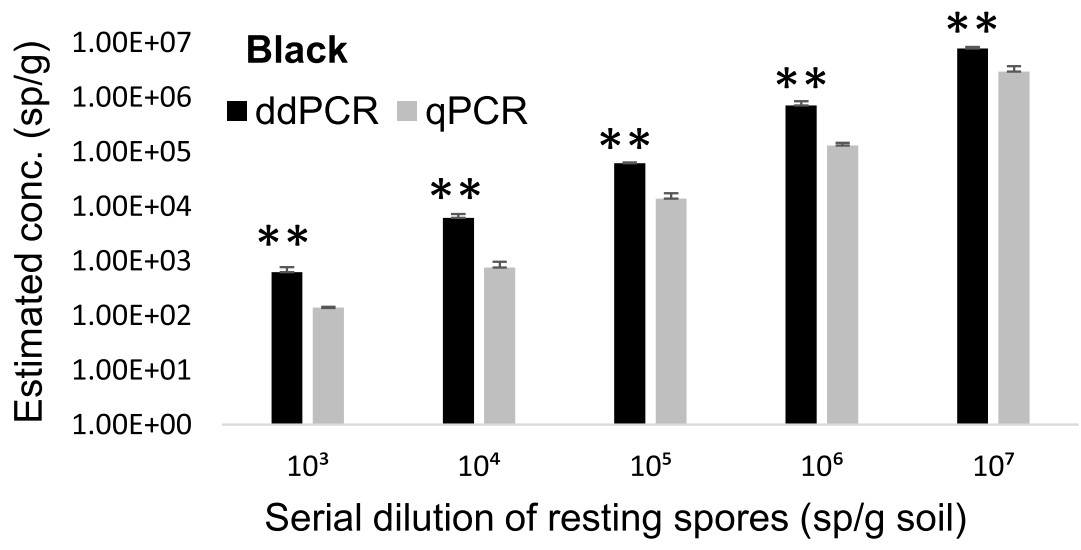

Fig. 5. Quantification of Plasmodiophora brassicae resting spores added to brown, dark brown, and black soils with droplet digital PCR (ddPCR) and quantitative PCR (qPCR). A, The soil types and $\mathrm{pH}$. B, Quantification of $P$. brassicae resting spores added to the three soil types at $10^{3}, 10^{4}, 10^{5}, 10^{6}$, and $10^{7}$ spores per gram with ddPCR and qPCR. Note that DNA amplification was inhibited for qPCR with black soil samples; the resting spore numbers were obtained after a 10 -fold dilution of $P$. brassicae genomic DNA extracted from black soil samples. ${ }^{*}$ Significant difference in spore numbers detected by the two methods ( $t$ test, $P<0.01$ ). 
spores of $P$. brassicae are small and lack visible ornamentation; therefore, the initial counts using a light microscope could be inaccurate (Cranmer 2015) to start with. Estimation of resting spore concentration using ddPCR seems optimal across the inoculum range of $10^{3}$ to $10^{7}$ per gram of soil, with the lowest limit at about $10^{2}$ spores per gram for artificially infested soil samples, which is slightly more sensitive than qPCR (Cao et al. 2007; Wallenhammar et al. 2012) or CPIC-PCR (Deora et al. 2015) as reported previously. This low detection limit is also close to the threshold level of inoculum (approximately $1 \times 10^{3}$ spores per gram of soil) required to produce clubroot symptoms consistently on a susceptible cultivar under conducive conductions (Donald and Porter 2009). Therefore, this ddPCR assay holds the promise for assessing clubroot risk in field soils based on inoculum density.

The ddPCR assay seems less reliable at $10^{8}$ spores per gram of soil or higher, where it can overestimate the spore concentration substantially. This problem is likely linked to the capacity of the droplet reader; pretreatment for ddPCR fractionates a DNA sample into approximately 20,000 droplets, and PCR amplification is assessed in each of these individual droplets (Pinheiro et al. 2011). Samples with a high concentration of target DNA likely approach the maximum capacity of droplets containing amplified DNA, which would likely affect the result. Samples with extremely high spore counts $\left(>10^{7}\right.$ spores per gram) may be diluted to remedy the problem and ensure that the ddPCR quantification occurs under optimal conditions. A similar broad range of accuracy was observed with ddPCR used to quantify the $P$. brassicae inoculum in soil from a heavily clubrootinfested field (Gossen et al. 2019).

When results of qPCR and ddPCR were compared for quantification of resting spores in infested potting mix, ddPCR estimated higher $(P<0.01)$ spore counts relative to qPCR1 or qPCR2 results in most of the samples tested. This differs from a 2019 study where ddPCR detected fewer resting spores than qPCR (Gossen et al. 2019). It is possible that the homogenization step added prior to the DNA extraction in this study improved the efficiency of cell lysing and DNA release. There is also the indication that PCR inhibitors exist in the potting mix that interfered with qPCR in the current tests by, for example, delaying the observed quantitation cycle. Because ddPCR is an end point quantification method, it is less affected by these inhibitory effects.

The comparison of qPCR and ddPCR results on P. brassicae resting spore quantification in different soil types indicates that ddPCR is a more accurate and versatile method. The estimates of $P$. brassicae inoculum based on ddPCR were not affected by the soil type, with almost the same estimated spore numbers for respective inoculum concentrations in the three soil types assayed. qPCR, however, estimated significantly lower spore numbers relative to ddPCR for almost all samples tested (Fig. 5B). Additionally, qPCR-estimated spore concentration was consistently higher in brown soil than in dark brown or black soil, and the DNA amplification was completely inhibited if the DNA samples from the black soil were not diluted. After DNA template dilution, qPCR estimated similar numbers of resting spores between black and dark brown soil samples, which were still lower than resting spore estimates obtained for brown soil samples. These results show that qPCR quantification of $P$. brassicae inoculum can be influenced by inhibitors present in natural soils; with the strongest effect in black soil. Appropriate dilution is required to alleviate the inhibitory effect in soil samples tested with qPCR. In contrast, ddPCR is generally not affected by the inhibitors in soils; there was no difference in estimated spore numbers among the three soil types (Supplementary Fig. S3), and the quantification closely matched the expected spore numbers in spiked soil samples at each level of inoculum concentration (Fig. 5B).

In conclusion, this study demonstrates the potential of using ddPCR to quantify the density of $P$. brassicae resting spores in soils; it provides robust estimates of resting spore concentrations in different soil types found commonly on the Canadian Prairies and may be versatile for uses in other soil types as well. This tool may be used to assess clubroot risks in diagnostic services and the impact of disease management practices, including crop rotation (Peng et al. 2015), use of bait crops (Ahmed et al. 2011), solarization, and fumigation (Hwang et al. 2017, 2018). Compared with qPCR and other molecular protocols, ddPCR seems more sensitive for detection and of $P$. brassicae inoculum in soils and more versatile for quantification of $P$. brassicae resting spores in different soil types because of reduced interference by PCR inhibitors present in soils.

\section{Acknowledgment}

The quantitative PCR1 was conducted at Pest Surveillance Initiative (laboratory; http://www.mbpestlab.ca/) under a service contract.

\section{Literature Cited}

Ahmed, H., Hwang, S., Strelkov, S., Gossen, B., Peng, G., Howard, R., and Turnbull, G. 2011. Assessment of bait crops to reduce inoculum of clubroot (Plasmodiophora brassicae) of canola. Can. J. Plant Sci. 91:545-551.

Al-Daoud, F., Gossen, B. D., Robson, J., and McDonald, M. R. 2017. Propidium monoazide improves quantification of resting spores of Plasmodiophora brassicae with qPCR. Plant Dis. 101:442-447.

Anders, J., Katarzyna, M.-S., Gunnar, B., and Ann-Charlotte, W. 2016. Quantitative PCR shows propagation of Plasmodiophora brassicae in Swedish long term field trials. Eur. J. Plant Pathol. 145:573-581.

Buczacki, S. T., and Moxham, S. E. 1983. Structure of the resting spore wall of Plasmodiophora brassicae revealed by electron microscopy and chemical digestion. Trans. Br. Mycol. Soc. 81:221-231.

Cangelosi, G. A., and Meschke, J. S. 2014. Dead or alive: Molecular assessment of microbial viability. Appl. Environ. Microbiol. 80:5884-5891.

Cao, T., Rennie, D. C., Manolii, V. P., Hwang, S. F., Falak, I., and Strelkov, S. E. 2014. Quantifying resistance to Plasmodiophora brassicae in Brassica hosts. Plant Pathol. 63:715-726.

Cao, T., Tewari, J., and Strelkov, S. E. 2007. Molecular detection of Plasmodiophora brassicae, causal agent of clubroot of crucifers, in plant and soil. Plant Dis. 91:80-87.

Cranmer, T. J. 2015. Vertical distribution of Plasmodiophora brassicae resting spores in soil and the effect of weather conditions on clubroot development. Master's thesis. University of Guelph, Guelph, ON, Canada.

Deora, A., Gossen, B. D., Amirsadeghi, S., and McDonald, M. R. 2015. A multiplex qPCR assay for detection and quantification of Plasmodiophora brassicae in soil. Plant Dis. 99:1002-1009.

Dixon, G. R. 2009. The occurrence and economic impact of Plasmodiophora brassicae and clubroot disease. J. Plant Growth Regul. 28:194-202.

Donald, C., and Porter, I. 2009. Integrated control of clubroot. J. Plant Growth Regul. 28:289-303.

Ernst, T., Kher, S., Stanton, D., Rennie, D., Hwang, S., and Strelkov, S. 2019. Plasmodiophora brassicae resting spore dynamics in clubroot resistant canola (Brassica napus) cropping systems. Plant Pathol. 68:399-408.

Faggian, R., and Strelkov, S. E. 2009. Detection and measurement of Plasmodiophora brassicae. J. Plant Growth Regul. 28:282-288.

Findlay, S. D., Vincent, K. M., Berman, J. R., and Postovit, L.-M. 2016. A digital PCR-based method for efficient and highly specific screening of genome edited cells. PLoS One 11:e0153901.

Gossen, B., Strelkov, S., Manolii, V., Rennie, D., Cao, T., Hwang, S., Peng, G., and McDonald, M. 2015. Spread of Plasmodiophora brassicae on canola in Canada, 2003-2014: Old pathogen, new home. Can. J. Plant Pathol. 37 403-413.

Gossen, B. D., Al-Daoud, F., Dumonceaux, T., Dalton, J. A., Peng, G., Pageau, D and McDonald, M. R. 2019. Comparison of techniques for estimation of resting spores of Plasmodiophora brassicae in soil. Plant Pathol. 68:954-961.

Gossen, B. D., Deora, A., Peng, G., Hwang, S.-F., and McDonald, M. R. 2014 Effect of environmental parameters on clubroot development and the risk of pathogen spread. Can. J. Plant Pathol. 36 (suppl 1):37-48.

Hindson, B. J., Ness, K. D., Masquelier, D. A., Belgrader, P., Heredia, N. J., Makarewicz, A. J., Bright, I. J., Lucero, M. Y., Hiddessen, A. L., Legler, T. C., Kitano, T. K., Hodel, M. R., Petersen, J. F., Wyatt, P. W., Steenblock, E. R., Shah, P. H., Bousse, L. J., Troup, C. B., Mellen, J. C., Wittmann, D. K., Erndt, N. G., Cauley, T. H., Koehler, R. T., So, A. P., Dube, S., Rose, K. A., Montesclaros, L., Wang, S., Stumbo, D. P., Hodges, S. P., Romine, S., Milanovich, F. P., White, H. E., Regan, J. F., Karlin-Neumann, G. A., Hindson, C. M., Saxonov, S., and Colston, B. W. 2011. High-throughput droplet digital PCR system for absolute quantitation of DNA copy number. Anal. Chem. 83:8604-8610.

Hwang, S. F., Ahmed, H. U., Strelkov, S. E., Gossen, B. D., Turnbull, G. D., Peng, G., and Howard, R. J. 2011. Seedling age and inoculum density affect clubroot severity and seed yield in canola. Can. J. Plant Sci. 91:183-190.

Hwang, S. F., Ahmed, H. U., Strelkov, S. E., Zhou, Q., Gossen, B. D., McDonald, M. R., Peng, G., and Turnbull, G. D. 2017. Suppression of clubroot by dazomet fumigant. Can. J. Plant Sci. 98:172-182.

Hwang, S. F., Ahmed, H. U., Strelkov, S. E., Zhou, Q., Gossen, B. D., Peng, G., Turnbull, G. D., and Fu, H. 2018. Effects of rate and application method on the efficacy of metam sodium to reduce clubroot (Plasmodiophora brassicae) of canola. Eur. J. Plant Pathol. 150:341-349. 
Hwang, S. F., Strelkov, S. E., Feng, J., Gossen, B. D., and Howard, R. J. 2012. Plasmodiophora brassicae: A review of an emerging pathogen of the Canadian canola (Brassica napus) crop. Mol. Plant Pathol. 13:105-113.

Kanagal-Shamanna, R. 2016. Digital PCR: Principles and applications. Pages 43-50 in: Clinical Applications of PCR, 3rd Ed. R. Luthra, R. R. Singh, and K. P. Patel, eds. Springer, New York, NY.

Kuypers, J., and Jerome, K. R. 2017. Applications of digital PCR for clinical microbiology. J. Clin. Microbiol. 55:1621-1628.

Little, T. M., and Hills, F. J. 1978. Agricultural Experimentation-Design and Analysis. Wiley and Sons, New York, NY.

Martin, C., Roberts, D., van der Weide, M., Rossau, R., Jannes, G., Smith, T., and Maher, M. 2000. Development of a PCR-based line probe assay for identification of fungal pathogens. J. Clin. Microbiol. 38:3735-3742.

Matheson, C. D., Gurney, C., Esau, N., and Lehto, R. 2010. Assessing PCR inhibition from humic substances. Open Enzyme Inhib. J. 3:38-45.

Monteiro, S., and Santos, R. 2017. Nanofluidic digital PCR for the quantification of norovirus for water quality assessment. PLoS One 12:e0179985.

Moxham, S. E., and Buczacki, S. T. 1983. Chemical composition of the resting spore wall of Plasmodiophora brassicae. Trans. Br. Mycol. Soc. 80:297-304.

Peng, G., Lahlali, R., Hwang, S.-F., Pageau, D., Hynes, R. K., McDonald, M. R., Gossen, B. D., and Strelkov, S. E. 2014. Crop Rotation, cultivar resistance, and fungicides/biofungicides for managing clubroot (Plasmodiophora brassicae) on canola. Can. J. Plant Pathol. 36 (suppl 1):99-112.

Peng, G., Pageau, D., Strelkov, S. E., Gossen, B. D., Hwang, S.-F., and Lahlali, R. 2015. A >2-year crop rotation reduces resting spores of Plasmodiophora brassicae in soil and the impact of clubroot on canola. Eur. J. Agron. 70:78-84.

Pennock, D. 2005. Field Handbook for Saskatchewan Soils. Department of Soil Science, University of Saskatchewan. http://www.usask.ca/saskatoon2010/ Saskatoon2010/Soil_Judging_Manual_files/Field\%20Handbook\%20for\% 20Saskatchewan \%20Soils\%20\%28Pennock,\%202005\%29.pdf

Pinheiro, L. B., Coleman, V. A., Hindson, C. M., Herrmann, J., Hindson, B. J., Bhat, S., and Emslie, K. R. 2011. Evaluation of a droplet digital polymerase chain reaction format for DNA copy number quantification. Anal. Chem. 84: 1003-1011.

Rački, N., Dreo, T., Gutierrez-Aguirre, I., Blejec, A., and Ravnikar, M. 2014. reverse transcriptase droplet digital PCR shows high resilience to PCR inhibitors from plant, soil and water samples. Plant Methods 10:42.

Razali, N. M., and Wah, Y. B. 2011. Power comparisons of Shapira-Wilk, Kolmogorov-Smirnov, Lilliefors and Aderson-Darling tests. J. Stat. Model. Anal. 2:21-33.

Rempel, C. B., Hutton, S. N., and Jurke, C. J. 2014. Clubroot and the importance of canola in Canada. Can. J. Plant Pathol. 36 (suppl 1):19-26.

Rennie, D. C., Holtz, M. D., Turkington, T. K., Leboldus, J. M., Hwang, S.-F., Howard, R. J., and Strelkov, S. E. 2015. Movement of Plasmodiophora brassicae resting spores in windblown dust. Can. J. Plant Pathol. 37:188-196.

Rennie, D. C., Manolii, V. P., Cao, T., Hwang, S. F., Howard, R. J., and Strelkov, S. E. 2011. Direct evidence of surface infestation of seeds and tubers by Plasmodiophora brassicae and quantification of spore loads. Plant Pathol. 60:811-819.

Strelkov, S. E., and Hwang, S. F. 2014. Clubroot in the Canadian canola crop: 10 Years into the outbreak. Can. J. Plant Pathol. 36 (suppl 1):27-36.

Strelkov, S. E., Hwang, S.-F., Manolii, V. P., Cao, T., Fredua-Agyeman, R., Harding, M. W., Peng, G., Gossen, B. D., McDonald, M. R., and Feindel, D. 2018. Virulence and pathotype classification of Plasmodiophora brassicae populations collected from clubroot resistant canola (Brassica napus) in Canada. Can. J. Plant Pathol. 40:284-298.

Wallenhammar, A. C. 1996. Prevalence of Plasmodiophora brassicae in a spring oilseed rape growing area in central Sweden and factors influencing soil infestation levels. Plant Pathol. 45:710-719.

Wallenhammar, A. C., Almquist, C., Söderström, M., and Jonsson, A. 2012. Infield distribution of Plasmodiophora brassicae measured using quantitative real-time PCR. Plant Pathol. 61:16-28.

Wallenhammar, A.-C., Gunnarson, A., Hansson, F., and Jonsson, A. 2016. Quantification of Plasmodiophora brassicae using a DNA-based soil test facilitates sustainable oilseed rape production. Plants 5:21. 